\title{
Quantification of liver iron overload disease with laser ablation inductively coupled plasma mass spectrometry
}

\author{
Philipp Kim, Sabine Weiskirchen ${ }^{1}$, Ricarda Uerlings ${ }^{1}$, Astrid Kueppers², Florian Stellmacher ${ }^{3}$, André Viveiros ${ }^{4}$, \\ Heinz Zoller ${ }^{4}$ and Ralf Weiskirchen ${ }^{*^{*}}$ (i)
}

\begin{abstract}
Background: Hereditary hemochromatosis is the most frequent, identified, genetic disorder in Caucasians affecting about 1 in 1000 people of Northern European ancestry, where the associated genetic defect (homozygosity for the p.Cys282Tyr polymorphism in the HFE gene) has a prevalence of approximately 1:200. The disorder is characterized by excess iron stores in the body. Due to the incomplete disease penetrance of disease-associated genotype, genetic testing and accurate quantification of hepatic iron content by histological grading of stainable iron, quantitative chemical determination of iron, or imaging procedures are important in the evaluation and staging of hereditary hemochromatosis.
\end{abstract}

Methods: We here established novel laser ablation inductively coupled plasma mass spectrometry protocols for hepatic metal bio-imaging for diagnosis of iron overload.

Results: We demonstrate that these protocols are a significant asset in the diagnosis of iron overload allowing iron measurements and simultaneous determination of various other metals and metalloids with high sensitivity, spatial resolution, and quantification ability.

Conclusions: The simultaneous measurement of various metals and metalloids offers unique opportunities for deeper understanding of metal imbalances. Laser ablation inductively coupled plasma mass spectrometry (LA-ICPMS) is a highly powerful and sensitive technique for the analysis of a variety of solid samples with high spatial resolution. We conclude that this method is an important add-on to routine diagnosis of iron overload and associated hepatic metal dysbalances resulting thereof.

Keywords: Metal, Iron, Hemochromatosis, Mass spectrometry, Molecular imaging, Liver, Iron overload, HFE, Diagnostic, Mutation

\section{Background}

Genetic iron storage diseases encompass a genetically heterogeneous group of disorders with strong environmental modifiers of disease expression [1]. Homozygozity for the c845G>A mutation within the HFE gene (OMIM: 613609) causing a substitution of the cysteine with a tyrosine residue in position 282 of the HFE gene product (p.Cys282Tyr) is, by far, the most frequent

\footnotetext{
* Correspondence: rweiskirchen@ukaachen.de

${ }^{1}$ Institute of Molecular Pathobiochemistry, Experimental Gene Therapy and Clinical Chemistry (IFMPEGKC), RWTH University Hospital Aachen, Pauwelsstr 30, D-52074 Aachen, Germany

Full list of author information is available at the end of the article
}

genetic form of iron overload. Autosomal recessive HFE-related iron overload is associated with typical clinical symptoms resulting from excess iron in several organs, mainly the liver representing the main storage site for iron. These include hepatomegaly, cirrhosis, hepatocellular carcinoma, diabetes mellitus, cardiomyopathy, hypogonadism, arthropathy, and increased skin pigmentation [2].

Genetic testing should be requested in patients with increased transferrin saturation, but results from population-based genetic screening studies have shown that the homozygosity for the p.Cys282Tyr polymorphism is associated with hemochromatosis in only $14 \%$ of

(C) The Author(s). 2018 Open Access This article is distributed under the terms of the Creative Commons Attribution 4.0 International License (http://creativecommons.org/licenses/by/4.0/), which permits unrestricted use, distribution, and 
individuals with this potentially disease-associated genotype. As hemochromatosis can also be caused by other mutation in the HFE gene or so called non-HFE hemochromatosis genes (HJV, HAMP, TFR2), homozygosity for p.Cys282Tyr is neither sufficient nor necessary for the diagnosis hemochromatosis. Accurate quantification of hepatic iron content by histological grading of stainable iron using Prussian blue or other dyes, direct chemical iron determination as well as magnetic resonance imaging (MRI) therefore remain essential diagnostic tools to detect and evaluate abnormal iron deposition in hereditary hemochromatosis $(\mathrm{HH})$.

Genetic testing for common HFE variants associated with iron overload (C282Y, H63D) is a simple and economical procedure to confirm the diagnosis $\mathrm{HH}$. A large variety of high-throughput methods for HFE genotyping are in daily routine use [3]. In addition, the repertoire of methods used for genetic diagnosis of $\mathrm{HH}$ contains other less commonly used methods such as PCR and reverse hybridization, direct sequencing, allele-specific PCR, PCR and high-resolution melting or single-stand conformational polymorphism, pyrosequencing and singe base extension [3]. Although classical liver biopsy with determination of hepatic iron concentration in fresh and paraffin-embedded tissue $[4,5]$ that has long been the gold standard for diagnosis of HH lost in importance, liver biopsy continues to have a very important diagnostic and prognostic implications in several hemochromatosis patients, especially in patients with suspected non-HFE hemochromatosis [6]. Such histochemical reactions are used to detect the presence of iron in biopsy specimens by forming insoluble complexes with appropriate dyes. Moreover, quantitative tissue iron determination and calculation of the hepatic iron index, defined as a quotient of micromoles or iron per gram of dry liver tissue and age of patient in years, was introduced to distinguish early hemochromatosis from alcoholic siderosis [7]. However, conventional tissue-ashing protocols, which rely on prolonged exposure to heat and caustic acids to achieve complete tissue decomposition are time-consuming, prone to sample loss and contamination, and potentially dangerous (e.g. release of hazardous fumes). Therefore, these procedures are for occupational medical reasons critical to adapt to routine clinical laboratories.

Most importantly, the subsequent determination of iron by atomic absorption spectrometry or chemically titration allows only the absolute quantitation of iron concentrations, but is not suitable to identify patterns, zonal gradients, or abnormal regional deposits or iron within the tissue. A histological hallmark of $\mathrm{HH}$ is that the accumulation and deposition or iron initially occurs in periportal hepatocytes (zone 1) in early phases of disease, while it extends to midzonal (zone 2) and centrilobular (zone 3) hepatocytes and biliary epithelium during progression of disease [8]. In contrast, transfusional iron overload, alcoholic siderosis or iron overload caused by SLC40A1 mutations are typically characterized by iron laden macrophages. Therefore, regional differences in hepatic iron concentrations are relevant providing information about the cause of iron overload, its stage and progression of the disease.

Recently, we established novel laser ablation inductively coupled plasma mass spectrometry (LA-ICP-MS)-based protocols for hepatic metal bio-imaging. Here we demonstrate that these protocols are a significant asset in the diagnosis of iron overload allowing iron measurements with high sensitivity, spatial resolution, and quantification ability. These protocols will be valuable in estimating liver iron content in all forms iron imbalances resulting from genetic disorders (hemochromatosis, $\beta$-thalassemia, and aceruloplasminemia), iron malabsorption, internal chronic bleeding, excessive menstrual bleeding, and nutritional deficiencies resulting for example from strict vegetarian food consumption.

\section{Methods}

\section{Human samples}

Percutaneous liver biopsy specimen analyzed in this study ( $n=4$ controls, $\mathrm{n}=4$ patients with confirmed iron overload) came from the Department of Medicine II (Gastroenterology and Hepatology) located at the University Innsbruck in Austria. All samples have been collected in the course of routine clinical care and were obtained by a standardized protocol. Ultrasound guided biopsy of the liver was carried out through an intercostal space in the right midclavicular line, where at least $5 \mathrm{~cm}$ liver parenchyma without large vessels were visible in expiratory hold. Before taking a biopsy with an 18-gauge $\times 4.5$ in. Trucut ${ }^{\circ}$ needle, skin disinfection and a sterile 4 $\mathrm{mm}$ skin incision was performed under local anesthesia with $5-10 \mathrm{ml} 1 \%$ lidocaine injected subcutaneously and under the liver capsule. Clinical data relevant on iron metabolism and HFE genetics are summarized in Table 1. The depicted values for transferrin, ferritin, and transferrin saturation in this table were determined in a laboratory using standard laboratory test. The serum and liver tissue iron were determined by atomic absorption spectroscopy following standard procedures. The study protocol conformed to the ethical guidelines of the 1975 Declaration of Helsinki as reflected in a priori approval by the appropriate institutional review committee. Informed consent for liver biospsy was obtained from all patients. Additional permission to measure the human liver samples by LA-ICP-MS was given by the ethics commission located at the Medical Faculty of the RWTH University Hospital Aachen (EK256/12 and EK186/15). 
Table 1 Patient's characteristics

\begin{tabular}{|c|c|c|c|c|c|c|c|c|c|c|}
\hline Cohort & Diagnosis & HFE Genetics* & Sex & Age & $\begin{array}{l}\text { Liver tissue } \\
\text { Fe }[\mu \mathrm{g} / \mathrm{g}]\end{array}$ & $\begin{array}{l}\text { Serum Fe } \\
{[\mu \mathrm{M}]}\end{array}$ & $\begin{array}{l}\text { Transferrin } \\
{[\mathrm{mg} / \mathrm{dL}]}\end{array}$ & $\begin{array}{l}\text { Ferritin } \\
{[\mu \mathrm{g} / \mathrm{L}]}\end{array}$ & Tranferrin saturation [\%] & $\begin{array}{l}\text { Anonymised } \\
\text { Sample no. }\end{array}$ \\
\hline \multirow[t]{4}{*}{ Iron overload } & HFE HH & $\begin{array}{l}\text { Y282/Y282 } \\
\text { H63/H63 }\end{array}$ & $M$ & 61 & 1117 & ND & 138 & 1950 & 95 & $\mathrm{H} 4$ \\
\hline & Non-HFE HH & $\begin{array}{l}\text { C282/C282 } \\
\text { H63/D63 }\end{array}$ & M & 55 & 2828 & 22.4 & 246 & 1850 & 36 & $\mathrm{H} 3$ \\
\hline & HFE HH & $\begin{array}{l}\text { Y282/Y282 } \\
\text { H63/H63 }\end{array}$ & $\mathrm{F}$ & 60 & 7600 & 33.7 & 158 & 934 & 85 & $\mathrm{H} 1$ \\
\hline & $\mathrm{HCV}$ & $\begin{array}{l}\mathrm{C} 282 / \mathrm{C} 282 \\
\mathrm{H} 63 / \mathrm{H} 63\end{array}$ & $\mathrm{~F}$ & 13 & NID & 21.4 & 246 & 52 & 35 & $\mathrm{H} 2$ \\
\hline \multirow[t]{4}{*}{ Normal iron status } & HBV, LTX & ND & M & 59 & NID & 16.9 & 254 & 52 & 26 & C4 \\
\hline & Ductopenia, LTx & ND & $\mathrm{F}$ & 69 & NID & 17.4 & 190 & 196 & 36 & $\mathrm{C} 1$ \\
\hline & LTX & ND & $\mathrm{F}$ & 53 & NID & 21.0 & 297 & 64 & 28 & C3 \\
\hline & $\mathrm{GvH}$ & ND & M & 36 & NID & 19.2 & 250 & 1431 & 31 & $\mathrm{C} 2$ \\
\hline
\end{tabular}

Abbreviations used: $F$ female, $G v H$ graft-versus-host, $H B V$ hepatitis B virus, $H C V$ hepatitis $C$ virus, HFE HH hereditary hemochromatosis, $L T x$ liver transplantation, $M$ male, $N A$ not applicable, $N D$ not determined, NID histologically no iron deposition, $N N$ not known. Normal laboratory reference ranges are: hepatic Fe $[\mu g / g$ dry

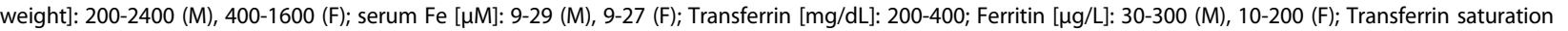
[\%]: 18-45. * HFE genotype constellations of patients subjected to LA-ICP-MS analysis were determined using TaqMan allelic discrimination assay [3, 9]

\section{Genetic analysis}

Genomic DNA was isolated from EDTA-anticoagulated whole blood. HFE genotyping for the p.Cys282Tyr and p.His63Asp polymorphism of patients subjected to LA-ICP-MS analysis was carried out using a validated TaqMan allelic discrimination assay using previously described protocols before [3, 9]. Lightcycler testing for HFE gene mutations depicted in Fig. 1 was done following established protocols [10-12]. Control DNA samples for the $\mathrm{C} 282 \mathrm{Y}$ variant site were taken from the respective kit system (Roche Diagnostics, Mannheim, Germany). In addition, a DNA sample from a patient carrying heterozygous $\mathrm{S} 65 \mathrm{C}$ and $\mathrm{H} 63 \mathrm{D}$ mutations were kindly provided by Genes4U AG (Neftenbach, Switzerland). Restriction fragment length polymorphism analysis with RsaI (Roche) and SnaBI restriction nucleases (New England Biolabs, Frankfurt am Main, Germany) for the C282Y variant and $B c l$ restriction nuclease (Roche) for the H63D variant was done following protocols reported elsewhere [13]. Sequencing of amplified products was done with primers spanning the variant site following standard procedures.

\section{Iron stain in liver tissue}

Ferrous ion $\left(\mathrm{Fe}^{2+}\right)$ was determined in paraffin-embedded samples following a standard Turnbull's blue staining procedures. In brief, tissue slides were first deparaffinized with xylene and rehydrated through a graded alcohol series. For reduction of ferric ion $\left(\mathrm{Fe}^{3+}\right)$ to ferrous $\left(\mathrm{Fe}^{2+}\right)$, the sections were first incubated in ammonium sulfide for $1 \mathrm{~h}$ and subsequently rinsed in distilled water. Subsequently, the slices were incubated in a 1:1 mixture of $20 \%$ potassium ferrocyanide and $1 \% \mathrm{HCl}$ solution for $10 \mathrm{~min}$. Subsequently, the slices were extensively washed in distilled water and counterstained in Nuclear Fast Red solution $(0.1 \% w / v$ with $5 \%$ aluminum sulfate).

\section{Sample preparation for LA-ICP-MS measurements}

The liver samples were cryo-cut into $30 \mu \mathrm{m}$ thick slices with a CM3050S cryomicrotome (Leica Biosystems, Wetzlar, Germany) on $-18^{\circ} \mathrm{C}$ cryo-chamber temperature and $-16{ }^{\circ} \mathrm{C}$ object area temperature, and thaw-mounted onto adhesive StarFrost $^{\circ}$ microscope slides (Knittel Glass, Braunschweig, Germany). Samples were dried and stored at room temperature.

\section{LA-ICP-MS set up and measurements}

Prior measurement, the mounted tissues were photographed using a Nikon Eclipse E80i research microscope (Nikon, Tokyo, Japan). The LA-ICP-MS measurements for elemental Bioimaging were performed in an experimental setup in which a high performing quadrupole Agilent 7900 ICP-MS (Agilent Technologies, Santa Clara, CA, USA) was combined with a laser ablating device, allowing the sample material to be ablated line by line with a focused laser beam (New Wave UP213, New Wave Research, Fremont, CA, USA). To keep the measurement time of the mass spectrometer as low as possible and for receiving highest spatial resolution during measurement, only isotopes of interests were selected. Standards for determination of element concentrations were produced from homogenized tissue spiked with varying concentrations of a standard salt solution. More details about the precise experimental setup used during the measurements, calibration and standard preparation are given elsewhere [14-16]. The precise parameters used in LA-ICP-MS measurement are summarized in Additional file 1: Table S1.

\section{Image generation of bio-metal distribution}

Isotope images were generated in Microsoft Excel with the help of the visualization tool ELAI (Excel Laser Ablation Imaging) as described elsewhere [16]. This 


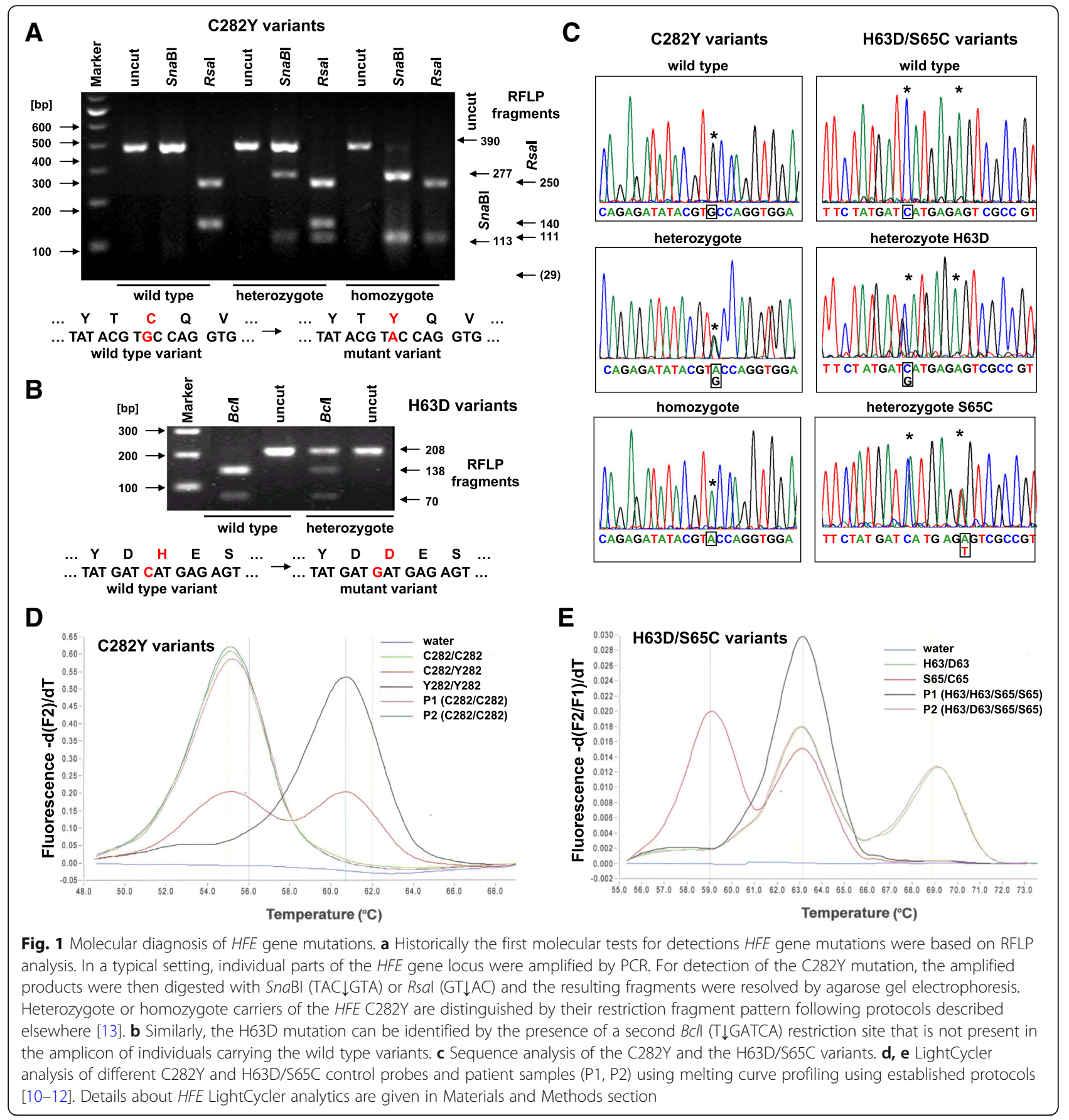

operating system allows the generation of images from mass spectrometry data without the need of any further additional software. This software for easy customizable semi-manual image generation, including documentation is available free of charge and can be downloaded elsewhere [16].

\section{Results}

During the last years, we established a large variety of molecular techniques for HFE genotyping including restriction fragment length polymorphisms (RFLP) analysis (Fig. 1a, b), genomic sequencing (Fig. 1c), and real-time polymerase chain reaction (PCR) analytics using fluorescence resonance energy transfer (FRET) probes (Fig. 1d, e). In most cases, these genetic tests are useful in confirming the diagnosis of $\mathrm{HH}$, especially in patients with clinical signs of $\mathrm{HH}$ or in patients with excessive accumulation of hepatic iron (Fig. 2).

Here we used the LA-ICP-MS technology to measure element concentrations in livers of 2 patients 


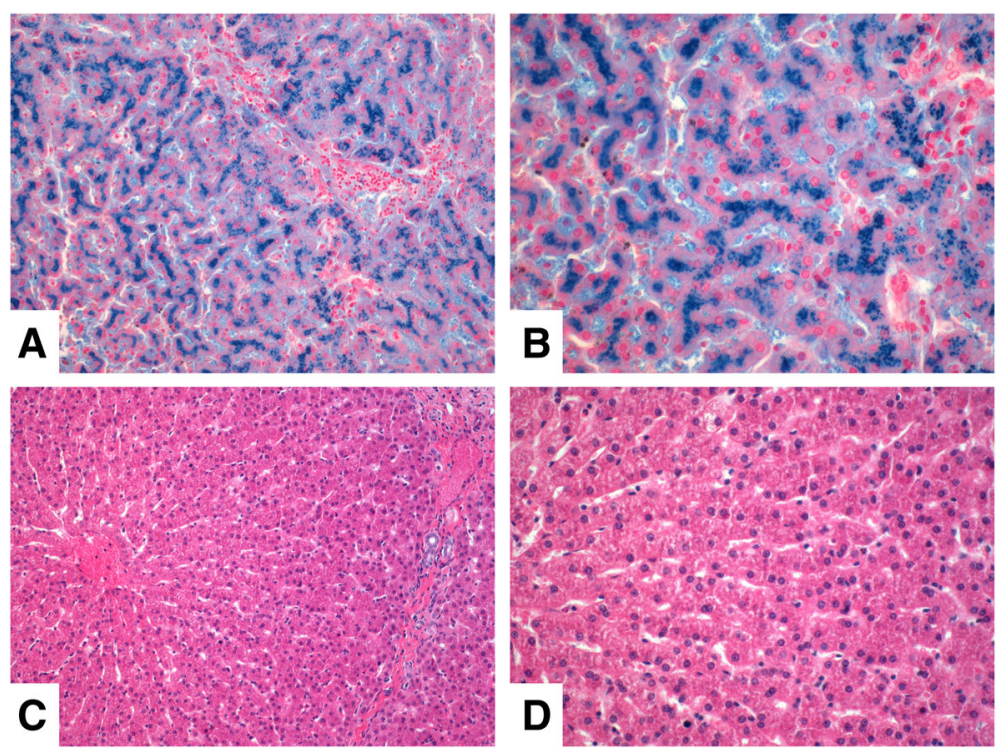

Fig. 2 Turnbull's blue stains and quantitative trace metal imaging in liver specimen by LA-ICP-MS. a, b Tumbull's blue stain of a liver specimen obtained from a patient suffering from hereditary hemochromatosis. The entire lobule has accumulated iron and the liver is at high risk of developing significant fibrosis. Magnifications are 100x in (a) and 200x in (b). For orientations, hematoxylin and eosin (H \& E) stains of normal subjects at same magnifications are shown in (c) and (d)

with $H F E$-associated $\mathrm{HH}(\mathrm{H} 1, \mathrm{H} 4)$ one patient with non-HFE hemochromatosis (H3), a non-p.Cys.282Tyr hemochromatosis patient $(\mathrm{H} 2)$ without evidence of iron overload as assessed by analysis of representative liver biopsy specimen of respective subject, and a patient with transfusional-induced iron overload after bone marrow transplantation (C2). In addition, liver specimens taken from liver transplant recipients without biochemical evidence of iron overload were taken as controls (C1, C3, and $\mathrm{C} 4)$. The overall morphology of respective biopsy samples is depicted in Fig. 3.

As expected, the overall concentration of iron was significant higher in samples taken from iron overload patients. While the iron concentration in three respective liver specimens were $18,992 \pm 8093 \mu \mathrm{g} / \mathrm{g}$ (H1), $2051 \pm$ $1490 \mu \mathrm{g} / \mathrm{g}(\mathrm{H} 3)$, and $8261 \pm 3405 \mu \mathrm{g} / \mathrm{g}$ (H4), the normal controls had overall lower concentrations $(132.3 \pm 126.0$ $\mu \mathrm{g} / \mathrm{g}(\mathrm{C} 1), 500 \pm 299 \mu \mathrm{g} / \mathrm{g}(\mathrm{C} 3)$, and $580 \pm 209 \mu \mathrm{g} / \mathrm{g}(\mathrm{C} 4))$ (Additional file 2: Table S2). Only the non-p.Cys282Tyr hemochromatosis patient $(\mathrm{H} 2)$ had somewhat lower concentration $(621 \pm 303 \mu \mathrm{g} / \mathrm{g})$, while one bone marrowtransplanted patient with transfusional iron overload (C2) had elevated quantities $(1534 \pm 535 \mu \mathrm{g} / \mathrm{g})$. Elevated iron concentrations in iron overload patients were also well-illustrated when we depicted the results as heat maps using the ELAI software (Fig. 4). Interestingly, the generated images revealed lower concentration of copper in HFE patients and large variations in manganese compared to the controls, while the concentration of zinc was comparable to those measured in healthy subjects.
However, since our measurements were only conducted in small groups, we actually do not know if these findings are of general validity or specific for the analyzed iron overload sample set $(n=4)$. We next tested the reproducibility of our measurements. Therefore, we measured the iron concentrations in eight serial cuts of the same HFE liver specimen (H4). In all eight cases, the determined iron concentration was visually the same showing the typical increased and uneven distribution of iron within the iron-overloaded tissue compared to samples collected from a healthy proband (Fig. 5).

To allow best visualization of measured metal concentrations in the experimental setup, it is optimal to set the ELAI scale during data processing into a range encompassing concentrations in which the estimated mean regional concentrations are centered in the middle of the selected scale. Exemplarily, when evaluating a measurement of a healthy subject with an estimated liver iron concentration lower than the threshold $60 \mu \mathrm{mol} / \mathrm{g}(\sim 3350.7 \mu \mathrm{g} / \mathrm{g})$ dry liver tissue [17], a scale ranging from 0 to $2500 \mu \mathrm{g} / \mathrm{g}$ to $0-6000 \mu \mathrm{g} / \mathrm{g}$ tissue is recommended for reconstruction of metal distribution maps (Fig. 6).

\section{Discussion}

Previously, we have optimized laser ablation inductively coupled mass spectrometry (LA-ICP-MS)-based methods for trace metal imaging in liver sections [14]. These protocols have multi-element capability suitable to simultaneously measure and quantify a large variety of different 


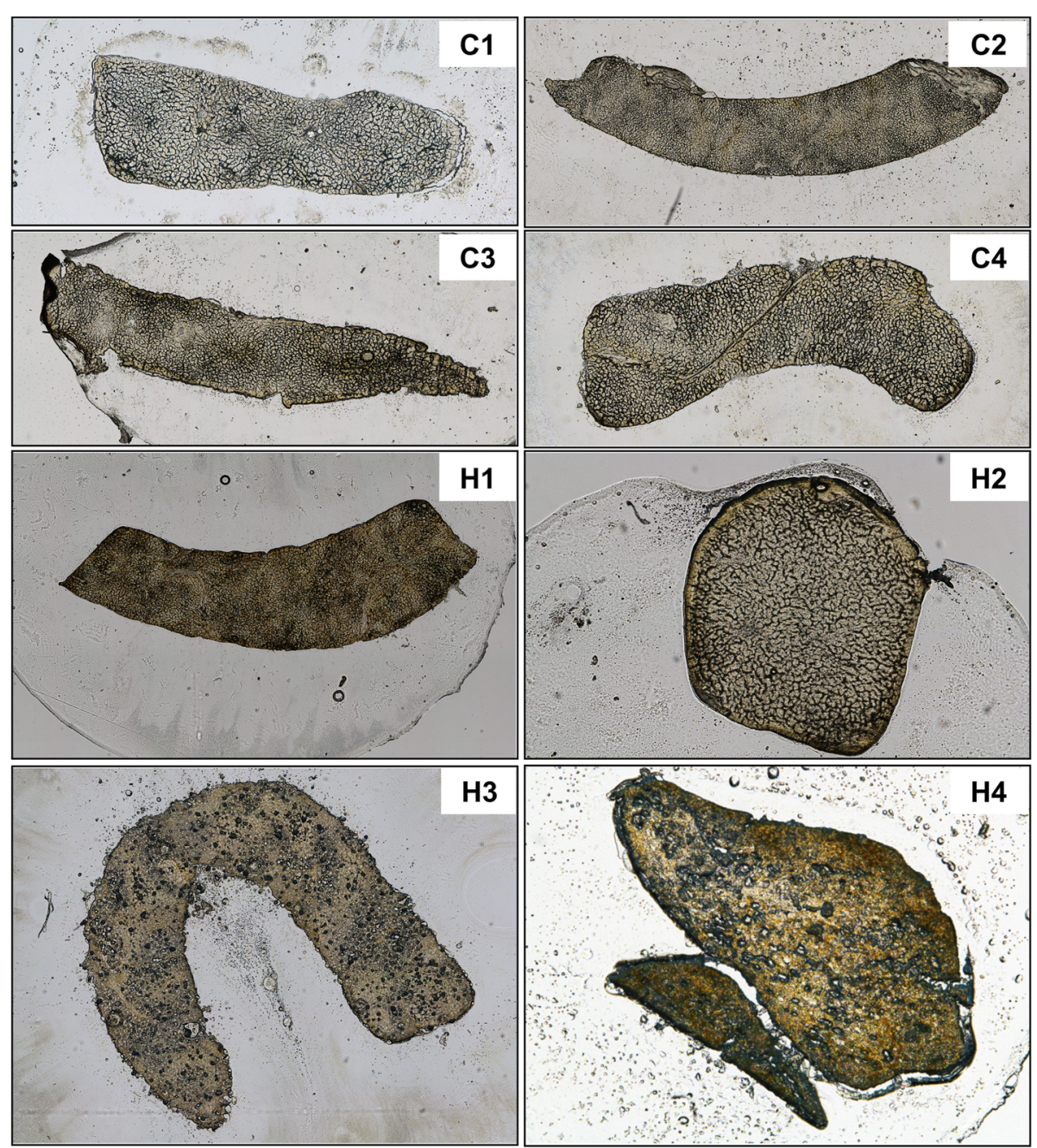

Fig. 3 Human liver samples analyzed. Control liver samples (C1-C4) and liver samples taken from confirmed iron overload patients (H1-H4) were collected by percutaneous liver biopsy. Representative cyrosections generated thereof for LA-ICP-MS metal bio-imaging are depicted

metals and metalloids within the tissue with high spatial resolution. In brief, a focused laser beam ablates a small quantity of biopsy material, and the aerosol produced is transported in an inert carrier gas stream to an ICP-MS, where it is then atomized and ionized. Subsequently, the different ions are separated according to their mass-tocharge ratio and quantified [15].

As demonstrated in our study, the LA-ICP-MS technique allows precise measurement and visualization of iron concentrations in high resolution. This is a great advantage when compared to other standard techniques. Quantitative measurements by spectrophotometry or semi-quantitative iron determinations by histology suffer from two limitations. The within-organ standard deviation (SD) of hepatic iron concentrations (HIC) can vary widely. Moreover, HIC values determined in microtome samples and biopsy-sized samples can have large coefficients of variations (CVs) reaching values of up to $71 \%$ in patients with end-stage cirrhosis [18]. It is also reasonable to speculate that histological stains are only semi-quantitatively because these are artificially lowered by removal of iron from the liver tissue during the fixing, washing and staining steps in the histochemical procedure. Likewise, the chemical determination of total iron in percutaneously obtained liver biopsy from patients with suspected primary iron overload identified by colorimetric analysis, flame atomic absorption and flameless atomic absorption spectrophotometry by a graphite furnace method revealed CVs ranging from 11 to $19 \%$ resulting from sample variation due to inhomogeneous distribution of iron through the liver [19]. Moreover, quantification of liver iron with MRI, computed tomography (CT), magnetic resonance spectroscopy (MRS), liver susceptometry, and relaxometry are partially limited. Although they are rapid, non-invasive, and cost effective techniques limiting the use of liver 

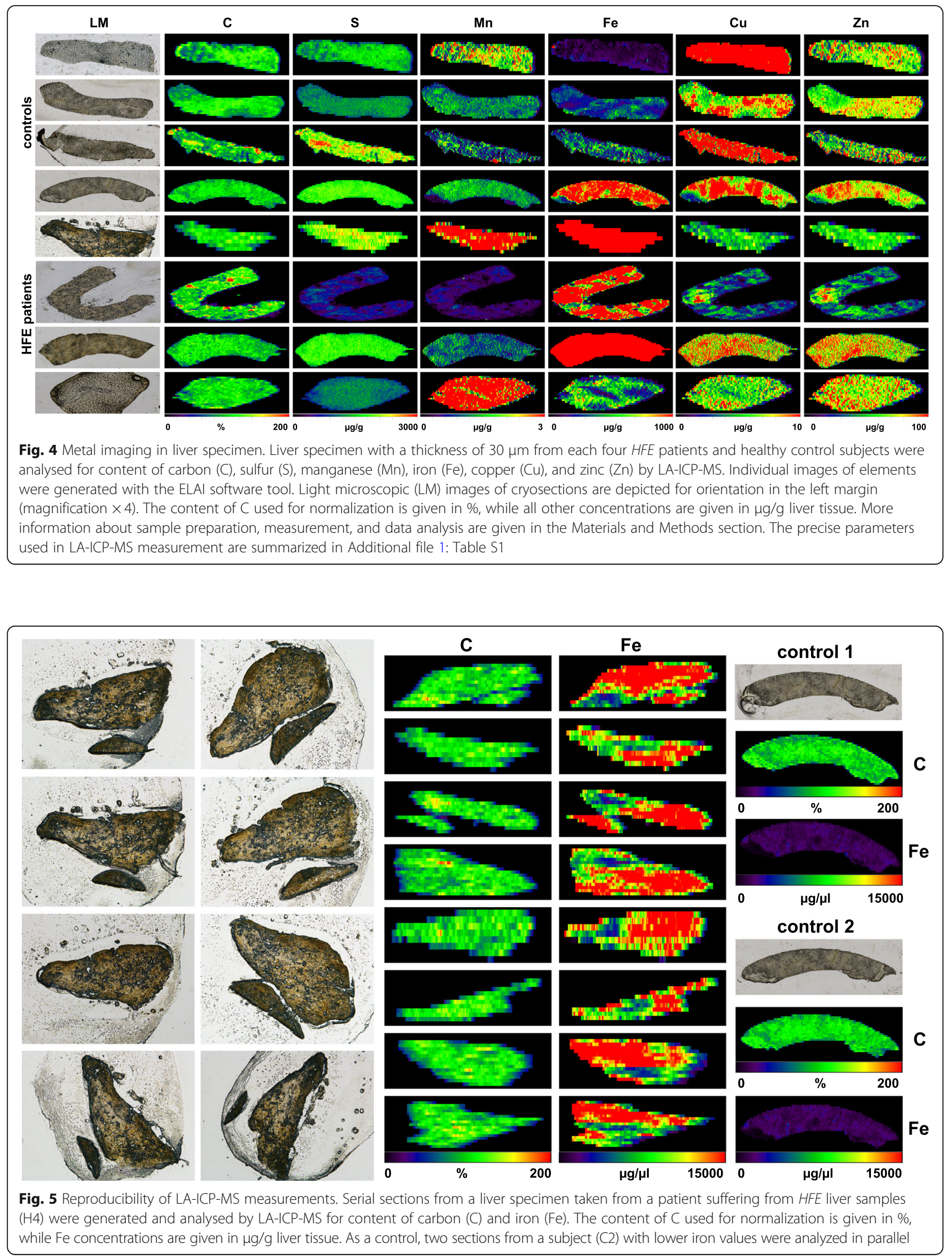

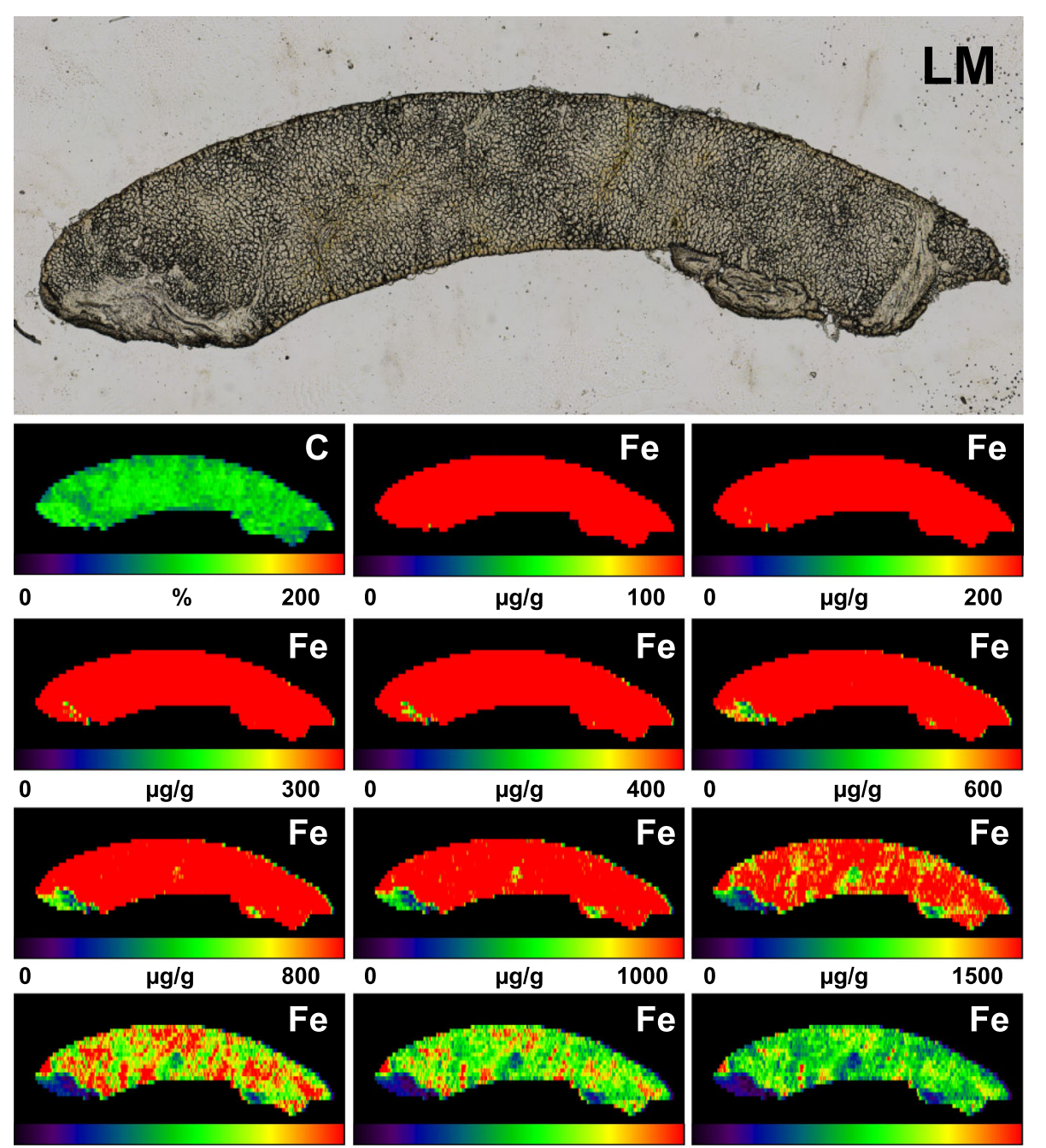

0

$\mu \mathrm{g} / \mathrm{g}$

$\mu \mathrm{g} / \mathrm{g}$

2500

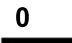

$\mu g / g$

3000
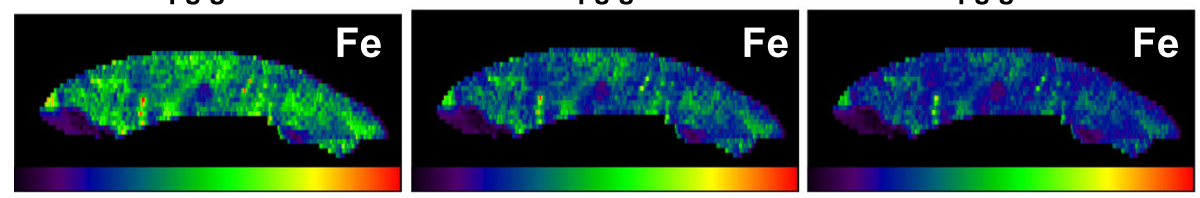

0

$\mu \mathrm{g} / \mathrm{g}$

4000
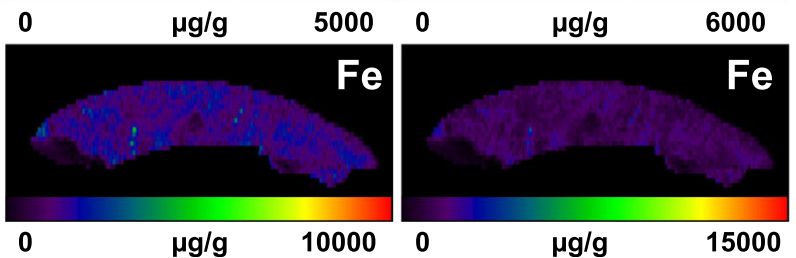

Fig. $\mathbf{6}$ Usage of different concentration ranges for ELAI image visualization. A liver specimen (taken from patient C2) was imaged by LA-ICP-MS for carbon (C) and iron (Fe). The different images for Fe were generated by using of different concentration ranges. Most favorable for image representation are ranges in which the mean concentration of the measured element is in the middle (i.e. in this case the green range) of the scale. A light microscopic (LM) image is given for orientation

biopsy in assessment of liver iron content, these methods have some analytical drawbacks [20, 21]. In particular, the occurrence of concomitant fat, inflammation and fibrosis within the liver corrupts the ability of gradient echo methods, often requiring the correlation with chemically determined liver iron concentration for establishment of empirical calibration curves. This provides a challenge in current MRI measurements of precise liver iron concentration in correcting for the transverse rate $\mathrm{R} 2\left(=1 / \mathrm{T}_{2}\right)$ and the faster and more 
sensitive $\mathrm{R} 2 *\left(=1 / \mathrm{T}_{2} *\right)$ cellular interference, including fibrosis, fat, inflammation, and other histologic changes in hepatic cellularity that are associated with tissue damage resulting from iron overload [22].

In addition, iron-overloaded livers can show iron heterogeneity over spatial scales spanning three orders of magnitude in regard to intracellular, intercellular and zonal compartments. These circumstances affect relaxation times during measurements, thereby introducing unavoidable errors [20].

In the last decade, several efforts were made to overcome these potential limitations in MRI and CT. Exemplarily, a new R2-MRI imaging technology termed "FerriScan" was introduced some years ago. This technology allows accurate measurement of liver iron concentration with high sensitivity and specificity and is unaffected by hepatic fat content, inflammation, fibrosis or cirrhosis [23, 24].

LA-ICP-MS imaging is a sophisticated tool for investigating the regional and spatial distribution of metals with high sensitivity, capability, and relatively good lateral resolution at micrometer resolution [25]. Therefore, this technology is becoming an essential tool in diverse biological research fields, and of course in clinical applications. We here have demonstrated that LA-ICP-MS is highly suitable to measure and localize iron concentrations of deposits in liver samples. Therefore, this technique might be relevant in the more precise determination of hepatic iron status, localization of iron deposits, or in HIC monitoring during $\mathrm{HH}$ therapy.

Presently, therapeutic phlebotomy is the standard clinical practice in the therapy of $\mathrm{HH}$ [26]. However, there is no evidence base on which to direct the optimal endpoint of this therapy. Actually, most clinicians attempt to achieve a target of serum ferritin lesser than $50 \mu \mathrm{g} / \mathrm{L}$. However, this value does not necessarily correlate with hepatic iron content. Possibly, the direct measurement of iron concentration and distribution in liver biopsy with LA-ICP-MS will be more suitable to mark a therapeutic endpoint in the treatment of $\mathrm{HH}$ patients.

The LA-ICP-MS protocols used in our study will be potentially relevant not only in estimating the degree of iron overload in hemochromatosis patient. There is a large set of

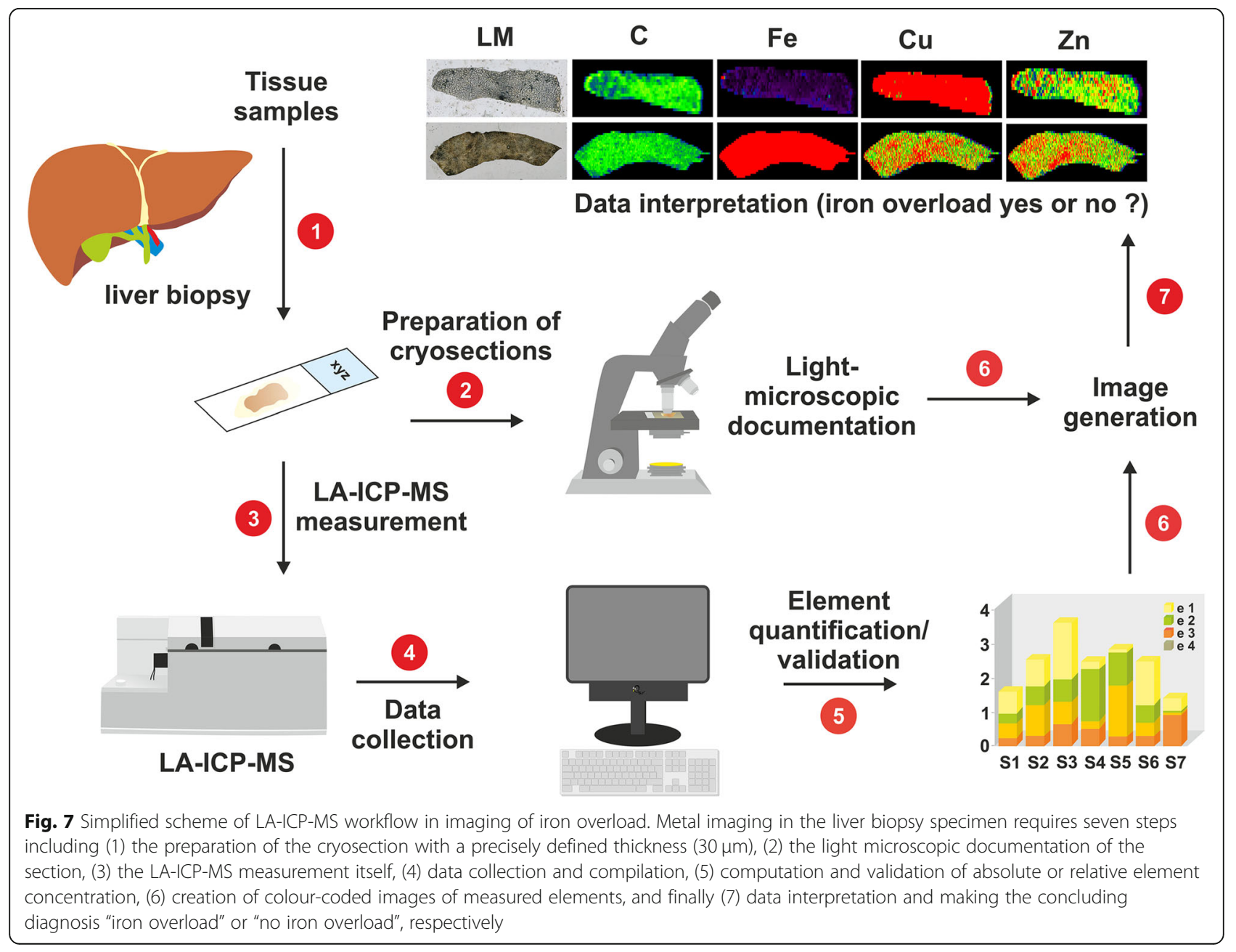


other genetic or acquired disorders that lead to strong imbalances in iron homeostasis. Beside hemochromatosis, system iron overload syndromes can have many other genetic or acquired origins including hereditary aceruloplasminemia, dyserythropoiesis, different forms of $\beta$-thalassemia, and several other conditions requiring multiple transfusions including myelodysplasia or hematopoietic stem cell transplantation resulting in iatrogenic iron overload [27-29]. Likewise, monosyndromic or polysyndromic sideroblastic anemias are known to develop both compartimental iron excess and systemic iron overload [27]. On the other side, iron malabsorption, internal chronic gastrointestinal bleeding, excessive menstrual bleeding, pregnancy, parasitic infection, and nutritional deficiencies resulting for example from strict vegetarian food consumption can provoke iron shortcomings in body's iron homeostasis $[30,31]$ that might be also reflected in lowered liver iron content.

\section{Conclusions}

In conclusion, our study aimed to improve the performance of LA-ICP-MS for routine measurement in $\mathrm{HH}$ diagnosis and other iron-related dysbalances. The respective workflow containing seven individual steps (Fig. 7) is straightforward and creates images that are easy to interpret. The data presented suggests LA-ICP-MS biometal imaging is a significant asset in the diagnostic evaluation of hereditary hemochromatosis, where the simultaneous measurement of iron and other metals offers unique opportunities for deeper understanding of the biology of hemochromatosis and iron overload.

\section{Additional files}

Additional file 1: Table S1. Operating parameters of LA-ICP-MS imaging of human liver samples. (DOC $45 \mathrm{~kb}$ )

Additional file 2: Table S2. Element concentrations in analysed liver samples. (DOC $40 \mathrm{~kb}$ )

\section{Abbreviations}

CV: Coefficient of variation; ELAl: Excel Laser Ablation Imaging; HFE: Gene encoding the hemochromatosis gene; $\mathrm{HH}$ : Hereditary hemochromatosis; LAICP-MS: Laser ablation inductively coupled plasma mass spectrometry

\section{Acknowledgements}

The authors are grateful to Marie-Claire Schifflers (IFMPEGKC, RWTH University Hospital Aachen, Germany) for sequence files and LightCycler curves.

\section{Funding}

RW is supported by grants from the German Research Foundation (DFG, SFB/TRR 57, projects P13 and Q3) and from the Interdisciplinary Centre for Clinical Research within the Faculty of Medicine at the RWTH Aachen University (IZKF Aachen, Project O3-1). The funders had no role in study design, data collection and analysis, decision to publish, or preparation of the manuscript.

\section{Availability of data and materials}

Data about characteristics of individual patients is stored at the Department of Medicine I (Gastroenterology, Hepatology and Endocrinology) at the Medical University of Innsbruck. Complete LA-ICP-MS data files used to prepare metal distribution maps are stored in the Institute of Molecular Pathobiochemistry, Experimental Gene Therapy and Clinical Chemistry (IFMPEGKC) at the RWTH University Hospital Aachen (UKA).

\section{Authors' contributions}

PK, RU and AK: performance and evaluating of LA-ICP-MS measurements; SW: generating of liver sections for LA-ICP-MS and preparation of figures; FS, performance of Tumbull's blue stain; AV and HZ: acquisition of liver specimen and clinical data; RW: conception of study and writing of manuscript. All authors have read and approved the manuscript.

\section{Ethics approval and consent to participate}

The study protocol conformed to the ethical guidelines of the 1975 Declaration of Helsinki as reflected in a priori approval by the appropriate institutional review committee. Informed verbal consent for liver biospsy was obtained from all patients. Additional ethical approval to analyse these anonymized liver specimens in our study was granted by the local Human Research Ethics Committees and the Institutional Review Board at the RWTH University Hospital Aachen (EK256/12 and EK186/15).

\section{Consent for publication}

Not applicable.

Competing interests

The authors have nothing to disclose.

\section{Publisher's Note}

Springer Nature remains neutral with regard to jurisdictional claims in published maps and institutional affiliations.

\section{Author details}

${ }^{1}$ Institute of Molecular Pathobiochemistry, Experimental Gene Therapy and Clinical Chemistry (IFMPEGKC), RWTH University Hospital Aachen, Pauwelsstr 30, D-52074 Aachen, Germany. ${ }^{2}$ Central Institute for Engineering, Electronics and Analytics, ZEA-3, Forschungszentrum Jülich, Jülich, Germany. ${ }^{3}$ Pathology, Research Center Borstel, Borstel, Germany. ${ }^{4}$ Department of Internal Medicine II, Medical University of Innsbruck, Innsbruck, Austria.

Received: 9 November 2018 Accepted: 14 November 2018 Published online: 04 December 2018

\section{References}

1. Asimakopoulou A, Weiskirchen S, Weiskirchen R. Pathogenesis, diagnostics, and treatment of hereditary haemochromatosis: a 150-year-long understanding of an iron overload disease. Eur Med J. 2017;2:122-33.

2. Bacon BR, Adams PC, Kowdley KV, Powell LW, Tavill AS. American Association for the Study of Liver Diseases: diagnosis and management of hemochromatosis: 2011 practice guideline by the American Association for the Study of Liver Diseases. Hepatology. 2011;54:328-33.

3. Porto G, Brissot P, Swinkels DW, Zoller H, Kamarainen O, Patton S, et al. EMQN best practice guidelines for the molecular genetic diagnosis of hereditary hemochromatosis (HH). Eur J Hum Genet. 2016;24:479-95.

4. Olynyk JK, O'Neill R, Britton RS, Bacon BR. Determination of hepatic iron concentration in fresh and paraffin-embedded tissue: diagnostic implications. Gastroenterology. 1994;106:674-7.

5. Beilby JP, Prins AW, Swanson NR. Determination of hepatic iron concentration in fresh and paraffin-embedded tissue. Clin Chem. 1999;45: 573-4.

6. Bassett ML, Hickman PE, Dahlstrom JE. The changing role of liver biopsy in diagnosis and management of haemochromatosis. Pathology. 2011:43:433-9.

7. Bassett ML, Halliday JW, Powell LW. Value of hepatic iron measurements in early hemochromatosis and determination of the critical iron level associated with fibrosis. Hepatology. 1986;6:24-9.

8. Batts KP. Iron overload syndromes and the liver. Mod Pathol. 2007;20(Suppl 1):S31-9.

9. Schranz M, Talasz H, Graziadei I, Winder T, Sergi C, Bogner K, et al. Diagnosis of hepatic iron overload: a family study illustrating pitfalls in diagnosing hemochromatosis. Diagn Mol Pathol. 2009;18:53-60. 
10. Tag CG, Gressner AM, Weiskirchen R. An unusual melting curve profile in LightCycler multiplex genotyping of the hemochromatosis H63D/C282Y gene mutations. Clin Biochem. 2001;34:511-5.

11. Geier A, Reugels M, Weiskirchen R, Wasmuth HE, Dietrich CG, Siewert E, et al. Common heterozygous hemochromatosis gene mutations are risk factors for inflammation and fibrosis in chronic hepatitis C. Liver Int. 2004;24: 285-94.

12. Bollhalder M, Mura C, Landt O, Maly FE. LightCycler PCR assay for simultaneous detection of the H63D and S65C mutations in the HFE hemochromatosis gene based on opposite melting temperature shifts. Clin Chem. 1999:45:2275-8.

13. Gottschalk R, Seidl C, Löffler T, Seifried E, Hoelzer D, Kaltwasser JP. HFE codon 63/282 (H63D/C282Y) dimorphism in German patients with genetic hemochromatosis. Tissue Antigens. 1998;51:270-5.

14. Boaru SG, Merle U, Uerlings R, Zimmermann A, Flechtenmacher C, Willheim C, et al. Laser ablation inductively coupled plasma mass spectrometry imaging of metals in experimental and clinical Wilson's disease. J Cell Mol Med. 2015;19:806-14.

15. Weiskirchen $\mathrm{R}$, Uerlings $\mathrm{R}$. Laser ablation inductively coupled plasma mass spectrometry in biomedicine and clinical diagnosis. Cell Mol Med: Open. access. 2015;1(1):3.

16. Uerlings $\mathrm{R}$, Matusch $\mathrm{A}$, Weiskirchen $\mathrm{R}$. Reconstruction of laser ablation inductively coupled plasma mass spectrometry (LA-ICP-MS) spatial distribution images in Microsoft excel 2007. Int J Mass Spectrom. 2016;395: 27-35.

17. Gandon Y, Olivié D, Guyader D, Aubé C, Oberti F, Sebille V, et al. Noninvasive assessment of hepatic iron stores by MRI. Lancet. 2004;363:357-62.

18. Emond MJ, Bronner MP, Carlson TH, Lin M, Labbe RF, Kowdley KV. Quantitative study of the variability of hepatic iron concentrations. Clin Chem. 1999;45:340-6.

19. Kreeftenberg HG, Koopman BJ, Huizenga JR, van Vilsteren $T$, Wolthers BG, Gips $\mathrm{CH}$. Measurement of iron in liver biopsies--a comparison of three analytical methods. Clin Chim Acta. 1984;144:255-62.

20. Sirlin CB, Reeder SB. Magnetic resonance imaging quantification of liver iron. Magn Reson Imaging Clin N Am. 2010;18:359-81.

21. Hernando D, Levin YS, Sirlin CB, Reeder SB. Quantification of liver iron with MRI: state of the art and remaining challenges. J Magn Reson Imaging 2014;40:1003-21.

22. Li J, Lin H, Liu T, Zhang Z, Prince MR, Gillen K, Yan X, et al. Quantitative susceptibility mapping (QSM) minimizes interference from cellular pathology in R2* estimation of liver iron concentration. J Magn Reson Imaging. 2018;48:1069-79.

23. House MJ, St Pierre TG, Milward EA, Bruce DG, Olynyk JK. Relationship between brain $\mathrm{R}(2)$ and liver and serum iron concentrations in elderly men. Magn Reson Med. 2010;63:275-81.

24. Britton L, Bridle K, Reiling J, Santrampurwala N, Wockner L, Ching H, et al. Hepatic iron concentration correlates with insulin sensitivity in nonalcoholic fatty liver disease. Hepatol Commun. 2018;2:644-53.

25. Pozebon D, Scheffler GL, Dressler VL. Recent applications of laser ablation inductively coupled plasma mass spectrometry (LA-ICP-MS) for biological sample analysis: a follow-up review. J Anal At Spectrom. 2017;32:890-919.

26. European Association for the Study of the Liver. EASL clinical practice guidelines for HFE hemochromatosis. J Hepatol. 2010;53:3-22.

27. Brissot P, Troadec MB, Loréal O, Brissot E. Pathophysiology and classification of iron overload diseases; update 2018. Transfus Clin Biol. 2018:S12467820(18)30095-8. https://doi.org/10.1016/j.tracli.2018.08.006. Epub ahead of print.

28. Asadov C, Alimirzoeva Z, Mammadova T, Aliyeva G, Gafarova S, Mammadov J. $\beta$-Thalassemia intermedia: a comprehensive overview and novel approaches. Int J Hematol. 2018;108:5-21.

29. Rostoker G, Vaziri ND. latrogenic iron overload and its potential consequences in patients on hemodialysis. Presse Med. 2017;46:e312-28.

30. Mirza FG, Abdul-Kadir R, Breymann C, Fraser IS, Taher A. Impact and management of iron deficiency and iron deficiency anemia in women's health. Expert Rev Hematol. 2018;11:727-36.

31. Camaschella C. Iron deficiency: new insights into diagnosis and treatment. Hematology Am Soc Hematol Educ Program. 2015;2015:8-13.

\section{Ready to submit your research? Choose BMC and benefit from:}

- fast, convenient online submission

- thorough peer review by experienced researchers in your field

- rapid publication on acceptance

- support for research data, including large and complex data types

- gold Open Access which fosters wider collaboration and increased citations

- maximum visibility for your research: over $100 \mathrm{M}$ website views per year

At $\mathrm{BMC}$, research is always in progress.

Learn more biomedcentral.com/submissions 